\title{
Livestock depredation by large predators and its implications for conservation and livelihoods in the Karakoram Mountains of Pakistan
}

\author{
Muhammad Zafar Khan, Babar Khan \\ Munammad Saeed Awan and Farida Begum
}

\begin{abstract}
Livestock depredation has particular significance in pastoral societies across the Himalayas. The dynamics of depredation by the snow leopard Panthera uncia and wolf Canis lupus were investigated by means of household surveys in the Hushey Valley, in the Karakoram Mountains of Pakistan. During 2008-2012 90\% of the households in the valley lost livestock to snow leopards and wolves, accounting for 0.8 animals per household per year. The cost of depredation per household was equivalent to PKR 9,853 (USD 101), or 10\% of the mean annual cash income. The majority (41\%) of predation incidents occurred in summer pastures, predominantly at night in open spaces. Of the total number of predation incidents, $60 \%$ were attributed to snow leopards and $37 \%$ to wolves; in $3 \%$ of cases the predator was unknown. As an immediate response to predation the majority of the local people $(64 \%, \mathrm{n}=99)$ opted to report the case to their Village Conservation Committee for compensation and only $1 \%$ preferred to kill the predator; $32 \%$ did not respond to predation incidents. The perceived causes of predation were poor guarding $(77 \%)$, reduction in wild prey (13\%), and livestock being the favourite food of predators (10\%). The most preferred strategies for predator management, according to the respondents, were enhanced guarding of livestock $(72 \%)$, followed by increasing the availability of wild prey (18\%), and lethal control $(10 \%)$. Livestock depredation causing economic loss may lead to retaliatory killing of threatened predators. For carnivore conservation and livestock security in this area we recommend improved livestock guarding through collective hiring of skilled shepherds and the use of guard dogs.
\end{abstract}

Keywords Canis lupus, human-carnivore conflict, Karakoram, Panthera uncia, predation

To view supplementary material for this article, please visit https://doi.org/10.1017/Soo30605316001095

Muhammad Zafar Khan (Corresponding author) and Farida Begum Department of Environmental Science, Karakoram International University, University Road, Gilgit-15100, Pakistan. E-mail zafar.khan@kiu.edu.pk

Babar KHan WWF-Pakistan, Gilgit, Pakistan

Muhammad Saeed Awan Department of Zoology, University of Poonch, Rawalakot, Azad Jammu \& Kashmir, Pakistan

Received 22 January 2016. Revision requested 17 March 2016.

Accepted 6 September 2016. First published online 15 February 2017.

\section{Introduction}

T ivestock herding is the primary land use and major Lsource of pastoral livelihoods across the transHimalayan rangelands (Fox et al., 1994; Mishra, 2001). The livestock sector contributes $20-35 \%$ of the total household income in the Himalaya-Karakoram-Hindu Kush mountain ranges of Gilgit-Baltistan, Pakistan (Beg, 2010) and $>80 \%$ of local people in this region depend upon livestock herding for their livelihoods. With a growing human population, livestock production has increased in GilgitBaltistan, including in the valleys surrounding Central Karakoram National Park (Khan et al., 2014). Although large predators and their prey species, including livestock, have coexisted in these mountainous landscapes since ancient times (Fox et al., 1994; Schaller, 1998), the increasing encroachment of pastoral activities on wildlife may lead to conflict (Rozen et al., 2012).

Livestock depredation by large mammalian predators results in significant economic losses for poor pastoral communities across the Himalayas, including in Pakistan (Malik, 1997; Hussain, 2000, 2003; Dar et al., 2009; Din \& Nawaz, 2011), and also threatens village-level food security (Rozen et al., 2012). Hence, predation on livestock is one of the primary reasons for human-carnivore conflict, and a challenge for conservation (Oli et al., 1994; Jackson et al., 1996; Mishra, 1997; Hussain, 2003; Jackson \& Wangchuk, 2004; Namgail et al., 2007). It becomes a major concern when livestock predation intensifies with increasing numbers of predators as a result of strict enforcement of conservation rules (Namgail et al., 2007; Alexander et al., 2016) or when domestic stock outnumber wild prey (Jackson \& Wangchuk, 2004), especially in montane areas where livestock herding is a substantial source of livelihood (Beg, 2010). The conflict intensifies if there is poor understanding of the social, economic and ecological interaction between pastoral communities and threatened wildlife species (Bagchi \& Mishra, 2006). We undertook this study, therefore, to investigate the socio-economic significance of livestock herding, the pattern of livestock herding and depredation, and the possible causes and implications of livestock depredation for local livelihoods and conservation of large predators with a view to devising appropriate conservation measures to create harmony between pastoral activities and conservation of mammalian predators. 


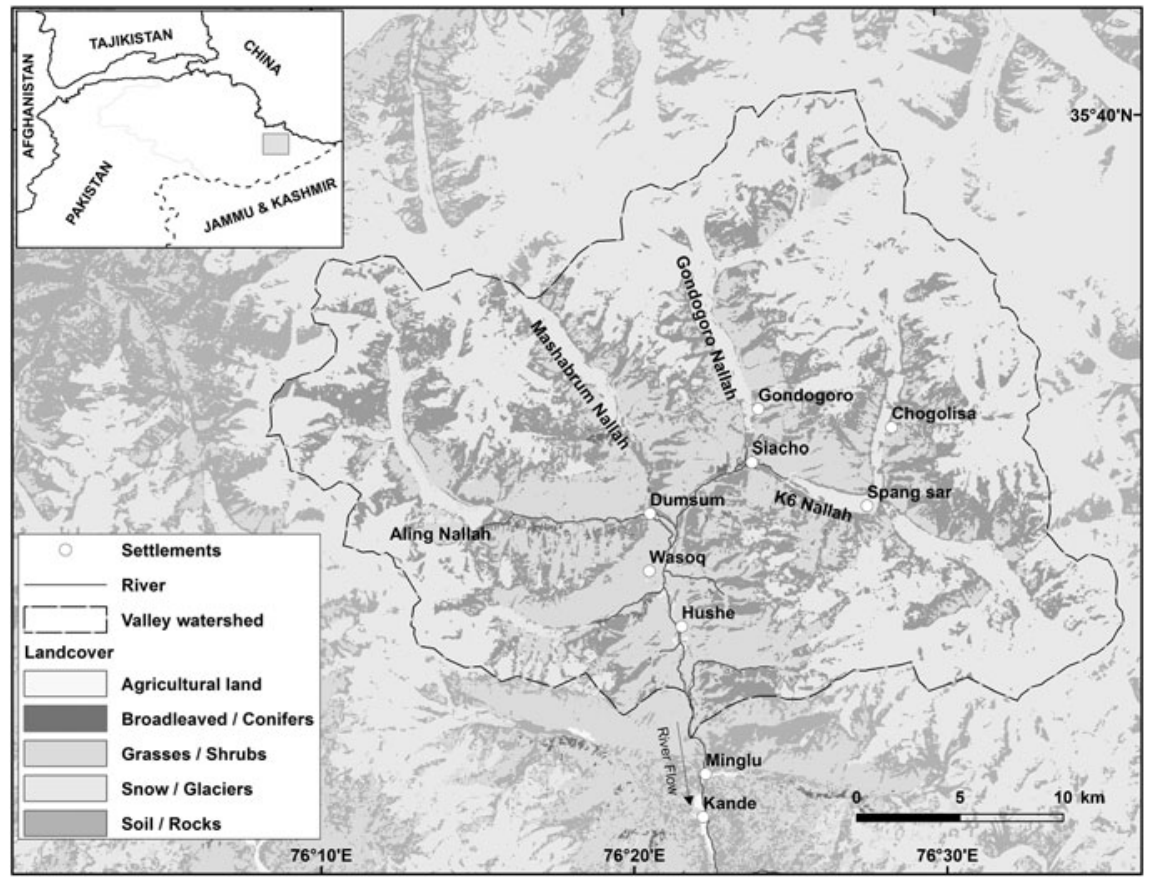

FIg. 1 Land cover in the Hushey Valley, Central Karakoram National Park, Pakistan. (Source: WWF-Pakistan, 2008)

\section{Study area}

The Hushey Valley $\left(832 \mathrm{~km}^{2}\right.$; WWF-Pakistan, 2008) forms the south-eastern part of the Central Karakoram National Park, $45 \mathrm{~km}$ north of Khaplu in Baltistan, Pakistan (Fig. 1). The valley lies at $2,500 \mathrm{~m}$ in the south and rises to $>5,000 \mathrm{~m}$ towards the north, including peaks of $>8,000 \mathrm{~m}$ (Khan et al., 2014). The area has a dry and cold desert mountain ecosystem, with most of the precipitation occurring in the form of heavy snowfall during November-March and the mean rainfall rarely exceeding $200 \mathrm{~mm}$; most of the area is unaffected by the summer monsoon (WWFPakistan, 2008). The valley is characterized by rugged terrain with steep slopes $\left(>50^{\circ}\right.$; Hussain, 2003). It is a refuge area not only for threatened species, such as the snow leopard Panthera uncia, but also for other important mammalian fauna, such as the Himalayan ibex Capra sibirica, the lynx Lynx lynx and the Tibetan wolf Canis lupus chanko (Roberts, 2005; Lovari \& Bocci, 2009). The predominant plants include species of Artemisia, Ephedra, Rosa, Hippophae, Myricaria and Berberis, and trees are dominated by species of Juniperus, Salix, Populus and Betula (WWF-Pakistan, 2008).

The valley is inhabited by c. 1,365 people (Government of Pakistan, 1998; with projected $2.5 \%$ annual increase) living in 130 households. Major sources of livelihood are agriculture and livestock herding, supplemented with cash incomes earned from tourism and services in the public sector (Hushey Village Conservation Committee, 2011). Since 1997 a community-based conservation programme has been operational in the valley, with support from various national and international conservation organizations. The valley is a Community Controlled Hunting Area, where limited trophy hunting of ibex is permitted, to earn revenue for local conservation and livelihood initiatives, such as the repair of irrigation water channels, tree plantation and paying honoraria to village wildlife guards. National and international hunters harvest 2-4 ibex each year for trophies, and 42 trophies were taken between 1997 and January 2012 (M. Aslam, pers. comm., 1 March 2012). A livestock insurance programme is also operational in the valley, with seed money capitalized in a local bank; the interest is used to provide compensation in cases of predation, following verification by a local livestock insurance committee.

\section{Methods}

Data were gathered by interviewing local community members in the Hushey Valley using a mix of qualitative (key informant interviews) and quantitative methods (structured interviews using a detailed questionnaire; Supplementary Material). These methods have been widely used to evaluate predation patterns, perceptions and human-carnivore interactions in Trans-Himalayan mountain ranges (e.g. Jackson et al., 1996; Namgail et al., 2007; Suryawanshi et al., 2013). The structured questionnaire was pre-tested in a pilot study with 15 respondents, and modified where necessary. The final questionnaire consisted of three main sections: (1) demographic and socio-economic profile of respondents, including the types, numbers, and economic value of livestock owned, (2) predation details, and (3) response to predation, opinion about causes of predation, and predator management. 
In structured interviews the respondents represented 99 of the 130 households in the valley and were contacted through door-to-door surveys during March-September 2013. Following informed consent, respondents took 3040 minutes to complete the questionnaire. With the help of local interpreters, questions were translated into Balti, the local dialect, when required.

The key informant interviews were conducted with employees of the Central Karakoram National Park Directorate and the Livestock \& Dairy Development Department, members of the Hushey Village Conservation Committee and people who had suffered large losses of livestock, especially within pens. This process helped us to understand the dynamics of village conservation programmes, their collective efforts, communal pastoral activities, equitable benefit sharing, and the challenges involved. Discussions were recorded using a voice recorder, with the interviewees' permission, and important points were also recorded in a notebook.

\section{Analysis}

All data were numerically coded and entered into SPSS $v .20$ (IBM, Armonk, USA). The financial loss incurred by each respondent from livestock depredation was calculated based on the mean local price (in PKR) during 2012, calculated for each type of livestock by dividing the total number of animals sold by total amount earned from that particular type of livestock (subsequently converted to USD; PKR $99=$ USD 1): PKR 42,500 for yak Bos grunniens, PKR 35,268 for cattle Bos taurus, including a crossbreed of yak and cow, PKR 13,478 for goats Capra aegagrus, and PKR 7,818 for sheep Ovis aries.

Demographic and socio-economic variables were coded as follows: age (young, $\leq 40$ years; old, $>40$ years); education (uneducated, no schooling or $<5$ years of basic formal education; educated, $\geq 5$ years of formal education); occupation (farmers; non-farmers); landholding status (low, $<1$ acre of cultivated land; medium, 1-2 acres of cultivable land; high, $>2$ acres of cultivable land); status of yearly cash income (low, < USD 2 per day; medium, USD 2-5 per day; high, $>$ USD 5 per day); status of livestock holding (low, $<$ 10 animals; medium, $10-20$ animals; high, $>20$ animals per household); predation losses in the last 5 years (no losses, no animals lost to predators; normal losses, 1-5 animals; high losses, $>5$ animals), and compensation for livestock losses (yes/no).

Data on livestock composition, grazing patterns, predation patterns, local perceptions of key predators, causes of predation, and predator management were compiled using descriptive and inferential statistics. A series of univariate analyses ( $\chi^{2}$ tests) were run to identify the association between response variables (perception of predator populations; causes of predation, response to predation incidents and predator management) and hypothesized predictors (age, education, income class, land and livestock holding, predation losses; Naughton-Treves et al., 2003; Dar et al., 2009). The response variables were coded as follows: perceptions of predator population ( $a$, increase; b, maintain; $c$, decrease; d, eliminate; e, don't know); response to predation ( $a$, did nothing; $b$, rushed to kill the predator; $c$, went to the Village Conservation Committee for help; d, reported the case to a government authority; e, other); causes of predation (a, not enough natural prey; b, livestock are the favourite food; c, livestock were not guarded and were exposed to the predator; d, livestock are easy to kill; e, don't know); appropriate management strategies (a, increased guarding of livestock; $b$, increase in wild prey base; c, habitat improvement measures; d, lethal control; e, other).

\section{Results}

In 2013 a total of 2,290 head of livestock were reared by $98 \%$ of the 130 households. Goats comprised $33 \%$, followed by sheep $(32 \%)$, cattle, including a crossbreed of cow and yak (30\%), yak (3\%) and equines ( $2 \%)$. The mean number of livestock head per household was 17.6 \pm SD 11.6. Most households (58\%) owned $>20$ animals; $32 \%$ owned $10-20$ animals, $25 \%$ owned $<10$ animals, and only $2 \%$ did not own any livestock. The grazing cycle comprised four phases: gradual upwards movement of livestock to spring pastures as the snow melted (May-June); partly attended and unattended grazing in summer pastures (July-August); gradual downwards movement in autumn (SeptemberOctober); free grazing in and around the village (November-April).

Of the 99 households interviewed, 90 confirmed they had lost livestock to mammalian predators, accounting for 375 kills during 2008-2012. The annual loss was $4.3 \%$ of the total livestock holdings in the village, or a mean of o.8 livestock head per household per year (with losses of 1-21 animals per household). The greatest loss was of domestic sheep $(47 \%)$, followed by goats $(42 \%)$, cattle $(8.3 \%)$, yak $(1.9 \%)$ and equines (0.3\%; Table 1). Of the total losses the majority $(58 \%)$ were reported to be female animals. Snow leopards were reportedly responsible for $223(60 \%)$ of the killings, and wolves for $140(37 \%)$; in $12(3 \%)$ cases the predator was unknown. Thus, snow leopards alone were responsible for more than half of predation incidents, accounting for $2.6 \%$ of the total livestock holdings in the valley.

A considerable portion (41\%) of the predation incidents reported occurred in summer pastures, $29 \%$ during spring and $21 \%$ during autumn in intermediate pastures, and only $9 \%$ in winter pastures. During heavy snowfall in winter livestock remained in sheds or close to settlements, under surveillance. A large number of killings (51\%) occurred at 
TABLE 1 Numbers of livestock killed by predators in the Hushey Valley, in the Central Karakoram National Park, Pakistan (Fig. 1) during 2008-2012.

\begin{tabular}{|c|c|c|c|c|c|c|}
\hline \multirow[b]{2}{*}{ Suspected predator } & \multicolumn{6}{|c|}{ Number and type of livestock } \\
\hline & $\begin{array}{l}\text { Yak Bos } \\
\text { grunniens }\end{array}$ & $\begin{array}{l}\text { Cattle Bos taurus } \\
\text { (including cross } \\
\text { breeds of yak \& cow) }\end{array}$ & $\begin{array}{l}\text { Goat Capra } \\
\text { aegagrus }\end{array}$ & $\begin{array}{l}\text { Sheep Ovis } \\
\text { aries }\end{array}$ & $\begin{array}{l}\text { Equine } \\
\text { Equus sp. }\end{array}$ & Total \\
\hline Snow leopard Panthera uncia & 6 & 23 & 96 & 98 & 0 & 223 \\
\hline Wolf Canis lupus & 1 & 8 & 56 & 74 & 1 & 140 \\
\hline Not known & 0 & 0 & 7 & 5 & 0 & 12 \\
\hline Total & 7 & 31 & 159 & 177 & 1 & 375 \\
\hline
\end{tabular}

TABLE 2 Annual \% livestock depredation by large predators in various locations in the Asian highlands, and financial loss per household.

\begin{tabular}{|c|c|c|c|c|}
\hline Study area & $\begin{array}{l}\% \text { of livestock } \\
\text { holding }\end{array}$ & $\begin{array}{l}\text { Predator } \\
\text { responsible }\end{array}$ & $\begin{array}{l}\text { Financial loss per } \\
\text { household per year } \\
\text { (USD) }\end{array}$ & Reference \\
\hline Taxkorgan Nature Reserve, Xinjiang, China & 5.9 & Snow leopard & & Schaller et al. (1987) \\
\hline Khunjerab National Park, Pakistan & 10 & $\begin{array}{l}\text { Snow leopard, } \\
\text { wolf }\end{array}$ & & Wegge (1989) \\
\hline Annapurna Conservation Area, Nepal & 2.6 & Snow leopard & $47-49$ & Oli et al. (1994) \\
\hline Mongolia & 9.6 & Snow leopard & & Schaller et al. (1994) \\
\hline Kibber Wildlife Sanctuary, India & 12 & $\begin{array}{l}\text { Snow leopard, } \\
\text { wolf }\end{array}$ & 128 & Mishra (1997) \\
\hline Baltistan, Pakistan & 2 & Snow leopard & & Hussain (2000) \\
\hline Sanjiangyuan, Qinghai, China & 1.3 & Snow leopard & & Li et al. (2013) \\
\hline $\begin{array}{l}\text { Hushey, Central Karakoram National Park, } \\
\text { Pakistan }\end{array}$ & 4.3 & $\begin{array}{l}\text { Snow leopard, } \\
\text { wolf }\end{array}$ & 101 & This study \\
\hline $\begin{array}{l}\text { Hushey, Central Karakoram National Park, } \\
\text { Pakistan }\end{array}$ & 2.6 & Snow leopard only & & This study \\
\hline
\end{tabular}

night in open spaces when livestock could not be penned for some reason; $36 \%$ of killings occurred in open pastures during grazing; $5 \%$ occurred inside pens; $4 \%$ occurred during movement from one pasture to another; and in $5 \%$ of cases the circumstances were unknown.

The total estimated economic loss incurred in Hushey from livestock depredation during 2008-2012 was PKR $4,926,596$ (USD 51,620). Thus, the mean annual loss incurred by a household from livestock depredation was PKR 9,853 (USD 101), which equates to $10 \%$ of the mean annual cash income of a household.

The responses of local people $(n=99)$ to incidents of predation varied significantly $\left(\chi^{2}=153, \mathrm{df}=4, \mathrm{P}<0.01\right)$. The majority $(64 \%)$ reported the incidents to their Village Conservation Committee to receive compensation from the livestock insurance fund, $32 \%$ did not respond, $1 \%$ reported to the relevant government department, and another $1 \%$ attempted to kill the predator. Among those who indicated no response $(n=32) 53 \%$ stated that they were unable to do anything, $31 \%$ were of the view that they could bear some losses of their livestock or tolerate the predators, and $16 \%$ provided no answer. There was significant difference in the perceived causes of predation $\left(\chi^{2}=84, \mathrm{df}=2\right.$,
$\mathrm{P}<$ o.001), which included poor or lax guarding practices $(77 \%)$, a reduction in wild prey $(13 \%)$, and livestock being the preferred food of predators (10\%).

The respondents considered snow leopards and wolves to be equally threatening to their livestock but were more afraid of snow leopards (53\%) than wolves ( $42 \%)$; $5 \%$ of respondents perceived no difference between the predators in relation to livestock depredation. Most of the respondents (88\%) were of the view that lynx were absent from the valley.

Regarding appropriate measures to manage predators, the majority of the respondents (72\%) suggested improved animal husbandry, such as guarded grazing and construction of predator-proof corrals; $18 \%$ preferred to promote habitat improvement measures to increase the natural prey base; and 10\% were in favour of lethal control. A majority $(71 \%)$ of the respondents who favoured lethal control were old and poorly educated.

\section{Discussion}

Our results show that the alleged losses of livestock to snow leopards and wolves are considerably higher in the study 
area than in most of the neighbouring mountain ranges (Table 2). Thus the mean annual monetary loss per household ( $10 \%$ of the mean cash income) is also relatively high, given the low cash income (mean USD 1,010 per household per year; for comparison, the sale of agricultural produce (cereals, vegetables and fruits) contributes $11 \%$ of the annual cash income per household. Sheep and goats were found to be the major victims of predation, as has also been reported in other parts of the Trans-Himalayan highlands (Namgail et al., 2007). That the majority of the animals killed were reported to be female can be attributed to the vulnerability of females to predators during lambing (Jackson et al., 1996). In the study area there is an association between the occurrence of predation and livestock herding patterns, which changes with the seasons, livestock types, and agro-pastoral activities. Livestock depredation increases in spring and reaches a maximum in summer, when livestock are moved to higher pastures away from the village settlements. It declines gradually with the downwards movement of livestock from higher pastures with the onset of winter. Similar patterns have also been observed in Annapurna, Nepal (Jackson et al., 1996). Although Dar et al. (2009) reported a significant and positive relationship between temperature and fatal attacks by leopards Panthera pardus, we assume the pattern observed in Hushey is a product of herding patterns rather than changing temperatures, with livestock being less guarded when they reach more open grazing grounds at higher altitudes. The impact of climate change cannot be ruled out, however, with an upwards shift in the snowline bringing predators and livestock into closer proximity.

The number of herders tending livestock in the study area is inadequate, with only 2-4 male shepherds herding $>$ 1,000 sheep and goats during the summer in high pastures, and 2-6 women tending a similar number of cattle in intermediate pastures. This problem is likely to intensify in the future as the younger generation becomes more involved in education, tourism and other off-farm income-generating opportunities.

More cases of predation $(60 \%)$ in the study area were attributed to snow leopards compared to wolves (37\%). However, such perceptions may not always reflect reality (Suryawanshi et al., 2013). Our study of food habits of large predators in Hushey (M.Z. Khan et al., unpubl. data) showed that wolves consumed a higher proportion of livestock than did snow leopards. There are two possible reasons for this difference between perception and actual predation: (1) an earlier livestock insurance programme run by a local NGO, Baltistan Wildlife Conservation and Development Organization, provided compensation for cases of predation by snow leopards only, and therefore local people tended to attribute more cases to snow leopards; (2) mass killings by snow leopards, either within a pen or in an open area, aggravated local people's perceptions of the threat posed by snow leopards. The respondents reported three mass killings by snow leopards during 20082012: two inside a pen and one in an open area. Snow leopards have been observed entering pens and killing large numbers of sheep or goats at a time (Namgail et al., 2007).

Despite the alleged livestock losses to snow leopards and the greater perceived threat, people in Hushey tend to tolerate snow leopards, indicating the effectiveness of community-based conservation programmes. However, conservation initiatives focused on the snow leopard may also result in increased populations of sympatric carnivores, leading to more human-carnivore conflict (Alexander et al., 2016). Despite attributing fewer livestock kills to wolves and perceiving them as a relatively smaller threat, people in Hushey exhibited negative behaviour towards wolves. This type of negative behaviour is likely to exacerbate persecution of wolves in the future and may also eventually affect snow leopards and other predators. For instance, local herders lace carcasses with poison to kill wolves or other unwanted predators, but this could also threaten other sympatric carnivores, especially snow leopards, whose habit is to return to an unfinished kill (Li et al., 2013).

According to the respondents the preferred strategies for predator management were improved guarding of livestock, coupled with measures to improve habitat conditions, such as rotational grazing and cultivation of fodder crops on more barren lands. Other recommended options included exploring income-generating opportunities for local communities that are not benefiting directly from a conservation programme (Mishra et al., 2003), and compensating for losses of livestock to predators by initiating communitybased livestock insurance schemes (Nowell \& Jackson, 1996), which have proved to be effective in similar mountain ecosystems; e.g. in the Spiti region of India (Mishra et al., 2003) and in Baltistan, Pakistan (Hussain, 2000; Rozen et al., 2012). Although not much encouraged within the local culture, a potential option that could be explored in Hushey is the use of improved breeds of guard dogs to ward off predators, as is also recommended in other snow leopard range countries (e.g. Nepal, Jackson et al., 1996; India, Namgail et al., 2007). However, guard dogs must be well kept, and fed and controlled appropriately, otherwise they become problematic to wildlife.

Livestock depredation by snow leopards and wolves is a serious economic concern for agro-pastoral communities in Karakorum and adjacent montane landscapes, and the situation could jeopardize community-based conservation initiatives by triggering human-carnivore conflict. Attacks on domestic livestock have been attributed to lax guarding practices, but may also be attributable to increasing carnivore populations as a result of stringent conservation measures (Alexander et al., 2016). The lax guarding is a product of a traditional transhumance grazing system that has been modified over time with changing livelihood options. The 
herding patterns evolved over centuries, adapting to local circumstances, but weakened over time as the number of shepherds declined and the younger generation pursued alternative livelihoods, such as growing potatoes as a cash crop. Now there are fewer and less skilled shepherds tending a large number of livestock, and we recommend that they be trained in anti-predator measures and employed for longer periods by paying them from the village conservation fund or from trophy hunting revenues.

Threats to large predators are interrelated; e.g. a poison used with the intention of killing one predator may also affect others. Thus, human-wildlife conflict is not a simple issue that can be addressed through a single species-focused conservation action but rather requires an integrative conservation initiative (e.g. a livestock insurance programme that compensates for predation by both snow leopards and wolves).

\section{Acknowledgements}

We thank WWF-Pakistan and Ev-K2-CNR for logistical support. We express our gratitude to Professor Sandro Lovari, University of Siena, Italy, for his technical guidance and review of this article. We appreciate the help of Ismail, Musa and Sakhawat with conducting interviews, and field staff of the Directorate of the Central Karakoram National Park and the local communities of Hushey for their assistance, support and hospitality during the fieldwork.

\section{Author contributions}

MZK conducted the field surveys and drafted the article. BK participated in some field surveys and reviewed the article. MSA helped to design and review the research design. FB helped with data analysis and a literature review.

\section{References}

Alexander, J.S., Cusack, J.J., Penguu, C., Kun, S. \& Riordan, P. (2016) Conservation of snow leopards: spill-over benefits for other carnivores? Oryx, 50, 239-243.

BAGCHI, S. \& Mishra, C. (2006) Living with large carnivores: predation on livestock by the snow leopard (Uncia uncia). Journal of Zoology, 268, 217-224.

BEG, G.A. (2010) Current status of pastoral systems in Gilgit-Baltistan and Chitral, Pakistan. In Pastoralism and Rangeland Management in Mountain Areas in the Context of Climate and Global Change. Proceedings of a Regional Workshop in Khorog and Kashgar, 14-21 July, 2010 (eds H. Kreutzmann, K. Abdulalishoev, L. Zhaohui \& J. Richter), GIZ, Feldafing, Germany.

Dar, N.I., Minhas, R.A., Zaman, Q. \& Linkie, M. (2009) Predicting the patterns, perceptions and causes of human-carnivore conflict in and around Machiara National Park, Pakistan. Biological Conservation, 142, 2076-2082.
Din, J.U. \& NAwaz, M.A. (2011) Status of snow leopard and prey species in Torkhow Valley, District Chitral, Pakistan. The Journal of Animal \& Plant Sciences, 21, 836-840.

Fox, J.L., Nurbu, C., Bhatt, S. \& Chandola, A. (1994) Wildlife conservation and land-use changes in the Trans-Himalayan region of Ladakh, India. Mountain Research and Development, 14, 39-6o.

Government of Pakistan (1998) Annual Census Report. Population Census Organization, Islamabad, Pakistan.

Hushey Village Conservation Committee (2011) Hushey Valley Conservation Plan. District Ghanche, Baltistan, Pakistan.

Hussain, S. (200o) Protecting the snow leopard and enhancing farmers' livelihoods: a pilot insurance scheme in Baltistan. Mountain Research and Development, 20, 226-231.

Hussain, S. (2003) The status of the snow leopard in Pakistan and its conflict with local farmers. Oryx, 37, 26-33.

Jackson, R.M., Ahlborn, G.G., Gurung, M. \& Ale, S. (1996) Reducing livestock depredation losses in the Nepalese Himalaya. In Proceedings of the 17th Vertebrate Pest Conference (eds R.M. Timm \& A.C. Crabb), pp. 241-247. University of California, Davis, USA.

JACKSON, R.M. \& WANGCHUK, R. (2004) A community-based approach to mitigating livestock depredation by snow leopards. Human Dimensions of Wildife, 9, 307-315.

Khan, M.Z., Awan, M.S., Bocci, A., Khan, B., Abbas, S.Y., Khan, G. \& AввAs, S. (2014) Population structure and grouping tendency of Asiatic ibex Capra sibirica in the Central Karakoram National Park, Pakistan. Journal of Biodiversity and Environmental Sciences, 5, 542-554.

Li, J., Yin, H., WANG, D., JiAGonG, Z. \& Lu, Z. (2013) Human-snow leopard conflicts in the Sanjiangyuan region of the Tibetan Plateau. Biological Conservation, 166, 118-123.

Lovari, S. \& Bocci, A. (2009) An evaluation of large mammal distribution on the CKNP. In Integrated Case Study of a Selected Valley in the Central Karakoram National Park, pp. 126-144. The Bargot Valley (HKKH Partnership Project) Ev-K2-CNR, Italy.

MALiK, M. (1997) Status and conservation of the snow leopard in Pakistan. In Proceedings of the Eighth International Snow Leopard Symposium (eds R. Jackson \& A. Ahmad), pp. 11-20. International Snow Leopard Trust, Seattle, USA.

Mishra, C. (1997) Livestock depredation by large carnivores in the Indian trans-Himalaya: conflict perceptions and conservation prospects. Environmental Conservation, 24, 338-343.

Mishra, C. (2001) High altitude survival: conflict between pastoralism and wildlife in the Trans-Himalaya. $\mathrm{PhD}$ thesis. Wageningen University, The Netherlands.

Mishra, C., Allen, P., McCarthy, T., Madhusudan, M.D., Bayarjargal, A. \& Prins, H.H.T. (2003) The role of incentive programs in conserving the snow leopard. Conservation Biology, 17, 1512-1520.

Namgail, T., Fox, J.L. \& Bhatnagar, Y.V. (2007) Carnivore-caused livestock mortality in Trans-Himalaya. Environmental Management, 39, 490-496.

Naughton-Treves, L., Grossberg, R. \& Treves, A. (2003) Paying for tolerance: rural citizens' attitudes toward wolf depredation and compensation. Conservation Biology, 17, 1500-1511.

Nowell, K. \& Jackson, P. (1996) Wild Cats: Status Survey and Action Plan. IUCN, Gland, Switzerland.

Oli, M.K., TAylor, I.R. \& Rogers, M.E. (1994) Snow leopard (Panthera uncia) predation of livestock: an assessment of local perceptions in the Annapurna Conservation Area, Nepal. Biological Conservation, 68, 63-68.

Roberts, T.J. (2005) Field Guide to the Large Mammals of Pakistan. Oxford University Press, Oxford, UK.

Rozen, T., Hussain, S., Mohammad, G., Jackson, R., JanečKa, J.E. \& MicheL, S. (2012) Reconciling sustainable development of 
mountain communities with large carnivores. Mountain Research and Development, 32, 286-293.

Schaller, G.B. (1998) Wildlife of the Tibetan Steppe. The University of Chicago Press, Chicago, USA.

Schaller, G.B., Li, H., Lu, H., Ren, J., Qiu, M. \& WanG, H. (1987) Status of large mammals in the Taxkorgan Reserve, Xinjiang, China. Biological Conservation, 42, 53-71.

Schaller, G.B., Tserendeleg, J. \& Amarsanaa, G. (1994) Observations on snow leopard in Mongolia. Proceedings of the International Snow Leopard Symposium, 7, 33-42.

Suryananshi, K.R., Bhatnagar, Y.V., Redpath, S. \& Mishra, C. (2013) People, predators and perceptions: patterns of livestock depredation by snow leopards and wolves. Journal of Applied Ecology, 50, 550-560.

Wegge, P. (1989) Khunjerab National Park in Pakistan: a case study of constraints to proper conservation management. In Conservation of
Mammals in Developing Countries. Proceedings of a Workshop in Association with the 5th International Theriological Congress (eds P. Wegge \& J. Thornback), Rome, Italy.

WWF-PAKISTAN (2008) Land Cover Mapping of the Central Karakoram National Park. WWF-Pakistan, Lahore, Pakistan.

\section{Biographical sketches}

Muhammad Zafar Khan's research interests include ecology and conservation of large mammals, community-based conservation and human-carnivore interactions. BABAR KHAN is interested in the distribution of mammals, protected area management and climate change. Muhammad SaEed Awan's research focuses on vertebrate pest management and sustainable agriculture. FARIDA BEGUM's research focuses on soil ecology, biology and water quality monitoring. 